\title{
The Study of Spatial Distribution of Land Use in the Yellow River Delta in China
}

\author{
Li Fan, Yusheng Gong*, Ting Duan, Jiayu Wang \\ School of Civil Engineering, University of Science and Technology Liaoning, Anshan, China \\ Email:1747450991@qq.com, ^38642709@qq.com, 43768127@qq.com, 1436744563@qq.com
}

How to cite this paper: Fan, L., Gong, Y.S. Duan, T. and Wang, J.Y. (2020) The Study of Spatial Distribution of Land Use in the Yellow River Delta in China. Journal of Geographic Information System, 12, 275-290. https://doi.org/10.4236/jgis.2020.124017

Received: June 12, 2020

Accepted: July 11, 2020

Published: July 14, 2020

Copyright (c) 2020 by author(s) and Scientific Research Publishing Inc. This work is licensed under the Creative Commons Attribution International License (CC BY 4.0).

http://creativecommons.org/licenses/by/4.0/ (c) (i) Open Access

\begin{abstract}
In this paper, Land at 8 OLI image data from 2013 to 2017 was interpreted by visual interpretation combined with supervised classification to extract the information of land use distribution in the Yellow River Delta in China. The characteristics of Land Use Cover Change (LUCC) in the past five years which were analyzed by land use spatial analysis method based on buffer zone were discussed to obtain the land use index trend of five land types in buffer zones at different distance. The land use transfer maps of 2013 and 2017 were made by using the geo-information mapping method. The spatial-temporal change rules and the development process of land use in the Yellow River Delta during the past five years were analyzed. According to the analysis results, the comprehensive index of land use degree in the study area was in the middle level. The land use transfer maps were mainly consisted of farmland and grassland. The change rate of bare land to vegetation was $20.21 \%$ and that of vegetation to bare land was $14.15 \%$. This study can provide effective basis for the scientific management of land and rational guidance for planning in this area.
\end{abstract}

\section{Keywords}

Buffer Zone Analysis, Land Use Degree, Regional Statistics, Geo-Information Map

\section{Introduction}

The great development of economy has led to rapid urbanization expansion in recent years. The increasing amount of land use data has brought about environmental damage and shortage of natural resources. With the launching of third land change survey and remote sensing monitoring in 2018, a comprehensive evaluation and analysis of land use and management is carried out in order 
to enhance the ability of land to participate in macro-control and further strengthen the strict scheme of cultivated land protection and land conservation. One of the key directions in future land use planning is to plan and utilize land resources rationally.

In recent years, a great amount of researches have been carried out by domestic and foreign scholars on the dynamic change of land use in time and space, which provided experience and evidence for identifying regional land use change objectively. In terms of spatial analysis, Li et al. [1] studied the spatial dependence and heterogeneity of land use/cover change in the Pearl River Delta using spatial autocorrelation analysis method. Through the calculation of global spatial autocorrelation, a single variable regional spatial autocorrelation and bivariate regional spatial autocorrelation, the results showed that the global spatial autocorrelation of land use/cover in the study area was weak and there was randomness in land use and development, and the difference of development degree within the study area was revealed. Ottinger et al. [2] used decision tree based pixel-by-pixel classification method to study the threat caused by the improvement of urbanization and the development of uncultivated land for the natural environment in the Yellow River Delta. The results showed that the surrounding built up area (including industry, infrastructure and residential area) has greatly increased and has replaced natural vegetation and cultivated land because of the rapid economic development. A large number of rivers used to irrigate, which has caused great damage to the delta ecosystem. In terms of technical means, Butt et al. [3] monitored the impact of land use change in the original Islamabad basin on hydrology and ecology by using the maximum likelihood method of supervisory classification. The results showed that the disorderly expansion of construction and agriculture area had led to the degradation of soil nutrients in the basin. Ganguly et al. [4] studied the land use/cover change in Maharashtra area in the past 40 years by using spatial statistical cluster analysis approach which indicated the transfer, rate, spatial pattern and spatial relationship of hot spots, and predicted the potential tendency of future Land-use/Land-cover (LULC) change. The proposed method of identifying hot spots of LULC transformation and the application of Getis-Ord $\mathrm{Gi}^{*}$ statistical test were different from the early model. This method can also be used to analyze the hotspots changes of other natural resources. Tran et al. [5] assessed the hotspot and landscape analysis of land use change in heat island cities, and applied MLP neural network and Markov chain model to predict future land cover change. They used changing factors from 2003 to 2015 in the model to simulate the land use and predict the land use change tendency. From the perspective of scenario simulation, Samie et al. [6] used the Dynamics of Land System (DLS) model to simulate the future land use pattern in Punjab province Pakistan from 2010 to 2030: 1) Business As Usual (BAU) scenario; 2) Rapid Economic Growth (REG) scenario and 3) Coordinate Environmental Sustainability (CES) scenario. The study results can be used to analyze land use change in scenario analysis and 
provide references for sustainable land use planning and management in Punjab Province. Based on random forest (RF) machine learning algorithm and existing highly automated method, Gounaridis et al. [7] classified hyperspectral data, disclosed three unbalanced stages of LUC development and reflected the socio-economic situation of each stage which indicated that the urban land increased rapidly and the farmland decrease to half of the original in Attica from 2003 to 2016. Liu et al. [8] used object-oriented and visual interpretation method to extract wetland information from the Yellow River Delta. Spatial analysis, dynamic index model and non-equidistant sequence gray model were used to analyze the spatial and temporal characteristics of wetlands. The results showed that wetland area and the degree of change varied from different regions, and the rate of wetland change in coastal areas was faster than that in inland areas. During the wetland dynamic change process, the transfer from wetland to non-wetland was higher than that from equivalent wetland. Ansari et al. [9] predicted the land use change rule of Meihan wetland and its surrounding environment based on artificial neural network (ANN) and Markov chain analysis. The results showed that rangeland and salt lake areas will decrease in the year 2030 compare to 2015, while, wetland, mine and manmade land may increase. This method has referenced value for future LULC image analysis and prediction. Barakat et al. [10] used remote sensing technology combined with GIS and Fuzzy Analytic Hierarchy Process (FAHP) to study the dynamic change of land use/cover in Beni-Mellal Town and its surrounding communities in Morocco. They calculating the weight of each LULC class by using FAHP method, and generated the map of the environmental impact of LULC. The impact of environment on LULC was analyzed by time and dual-time sequence. Guo et al. [11] used land use transfer matrix, land use change maps and ESV hot spot analysis tools based on analyzing the land use change and ESV in Funiu Mountain from 1990-2015 to combine land use change maps with ESV hot spot analysis and spread them to a smaller grid space, which effectively reflected the impact of LUC on ESV and provided a new research framework for studying the interaction between LUC and ESV in space. Li and Kuang [12] simulated the urban land expansion scenario in Beijing, Tianjin and Hebei Province based on LTM model and validated the results with the urban land use data in 2015. Considering the urban land use demand in Beijing, Tianjin and Hebei Province from 2020-2050, they delineated the spatial distribution of future urban land expansion and the expansion speed of urban land in the future 35 year was characterized by "fast-slow-fast-slow".

With the rapid development of regional social economy, urbanization speed, combined with the sedimentation epeirogenic natural succession process, the Yellow River Delta become one of the most active areas in China, And the land cover change in the Yellow River Delta were studied by some scholars In the past, but there is less relevant results in recent years. Previous studies mainly focused on spatial analysis of rivers and cities, but lacked of quantitative research. 
Little or no detailed study on land use change within the study area is implemented. This study established the relationship between water body, vegetation, building and land use distribution. At the same time, buffer zone analysis was adopted for the comprehensive index of land use types. Spatial analysis and geo-information map were introduced to quantitatively study the transfer direction of different land types. Finally, the spatial and temporal changes of different land use types were systematically discussed, which were expected to provide theoretical basis and decision-making reference for the sustainable use of land resources and ecological environment protection in the Yellow River Delta.

\section{Experiment and Analysis}

\subsection{Data and Material}

\subsubsection{Study Area}

The Yellow River Delta $\left(117^{\circ} 31^{\prime}-119^{\circ} 18^{\prime} \mathrm{E}, 36^{\circ} 55^{\prime}-38^{\circ} 16^{\prime} \mathrm{N}\right)$ is located in the alluvial fan area formed by the alluvial process of the Yellow River below Lijin County in Shandong Province. It is fun shaped which covers an area of 5450 square kilometers, with Lijin County as the apex, Tuhai River estuary in the north, Xiaoqing River in the South and Dongying City as the main body. The area is flat with an average elevation of less than 10 meters. The Yellow River Delta is located in the mid-latitude region and the warm temperate zone. Its back land is facing the sea. Under the joint influence of Eurasia and the Pacific Ocean, it is located in the warm temperate semi-humid continental monsoon climate zone. The location of the study area was shown in Figure 1.

\subsubsection{Data Resources}

The land cover change analysis in this study was based on Lands at 8 OLI images of five consecutive years $(2013,2014,2015,2016$ and 2017) with resolution of 30 $\mathrm{m} \times 30 \mathrm{~m}$. In the convenience of land use type extraction we selected the clear images in June, July, August with abundant vegetation information and less than $20 \%$ of cloud cover. Point of Interest (POI) data downloaded from the Resource and Environmental Science Data Center of the Chinese Academy of Sciences was used as data resource of land use analysis in the Yellow River Delta and 1 $\mathrm{km}$ raster data set of remote sensing land use status in Shandong Province was used as reference data. The image information was shown in Table 1.

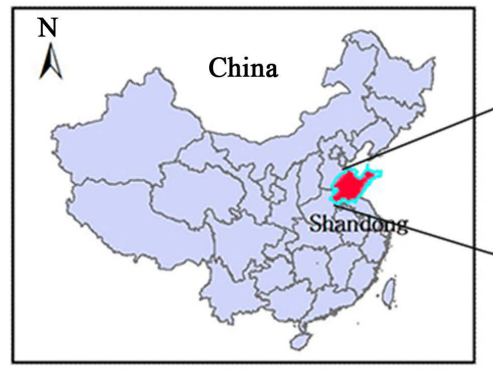

$117^{\circ} 0^{\prime} 0^{\prime \prime} \quad 118^{\circ} 0^{\prime} 0^{\prime \prime} \quad 119^{\circ} 0^{\prime} 0^{\prime \prime} \quad 120^{\circ} 0^{\prime} 0^{\prime \prime}$

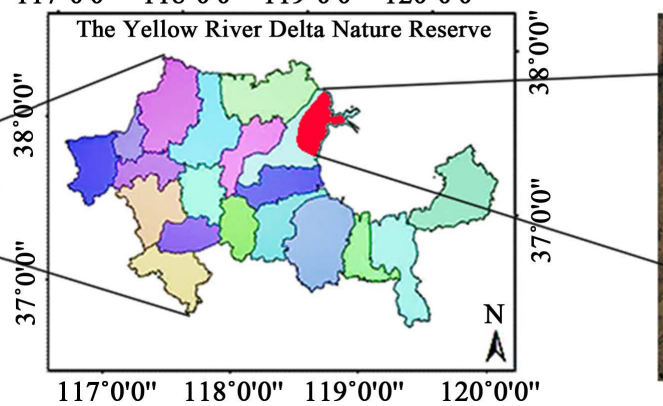

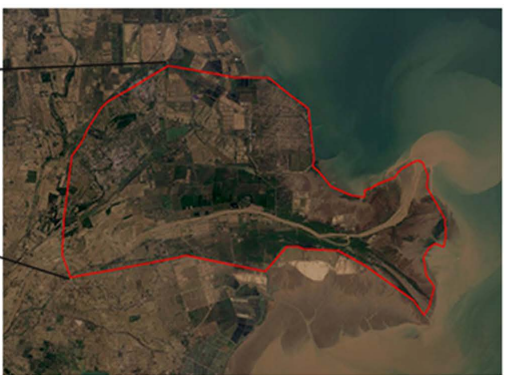

Figure 1. Location of the study area. 
Table 1. Satellite remote sensing data in the study area.

\begin{tabular}{ccccc}
\hline Data Information & Date & Path/Row & Resolution $(\mathrm{m})$ & Cloud cover (\%) \\
\hline LC81210342013166LGN00 & 2013.6 .15 & $121 / 34$ & 30 & 14.89 \\
LC81210342014201LGN01 & 2014.7 .20 & $121 / 34$ & 30 & 2.7 \\
LC81210342015156LGN00 & 2015.6 .5 & $121 / 34$ & 30 & 16 \\
LC81210342016223LGN01 & 2016.8 .10 & $121 / 34$ & 30 & 5.08 \\
LC81210342017193LGN00 & 2017.7 .12 & $121 / 34$ & 30 & 9.22 \\
\hline
\end{tabular}

\subsection{Data Pre-Processing and Classification}

In this research, remote sensing image preprocessing included radiation calibration, FLAASH atmospheric correction and image vector clipping. Figure 2 showed the flowchart of land use change analysis.

Hasmadi et al. [13] used contrast enhancement and multiband combination to improve the quality of images in supervised classification. In order to improve the classification accuracy, multiband was combined to distinguish different types of ground objects in this study. And 543 bands were mainly used to synthesize standard pseudo-color image, from which the color of ground features was vivid and it was beneficial for vegetation (red) and water body classification. We chose the method of combining visual interpretation with nearest neighbor method in supervised classification to interpreted remote sensing data and referred to the classification standard of land use status (GB/T 21010-2007) and the national remote sensing land use/cover classification system. We also established an interpretation sign in Google Earth software. There is few cloud cover in the study area, the images are relatively clear. Referring to China's land use classification standards, considering the actual situation of land use in the study area and refers to interpretation symbol of the coastal wetlands in the Yellow River Delta [14], the land use was divided into five types: water body, vegetation, bare land, construction area and other land [15].

\subsection{Analysis of Spatial Distribution Pattern}

This paper established a buffer zone after classifying five types of land use: water body, vegetation, bare land, construction area and other land in 2013-2017 [16] [17]. The land use degree of buffer zones in different land use types was analyzed by introducing the method of regional statistics. Comprehensive index of land use degree reflected the actual land use status. Liu [18] put forward the quantification method of land use degree, which was expressed as follow:

$$
L_{a}=100 \times \sum A_{i} \times C_{i}, \quad L_{a} \in[100,400]
$$

In the equation, $A_{i}$ and $C_{i}$ are the grading index of grade land use degree i and grading area percentage respectively. The land use grading assignment table can be seen in Table 2. According to Equation (1), the comprehensive quantitative index system of land use degree is a continuous change index from 100 to 400 . Since comprehensive index of land use degree is a continuous function with the 


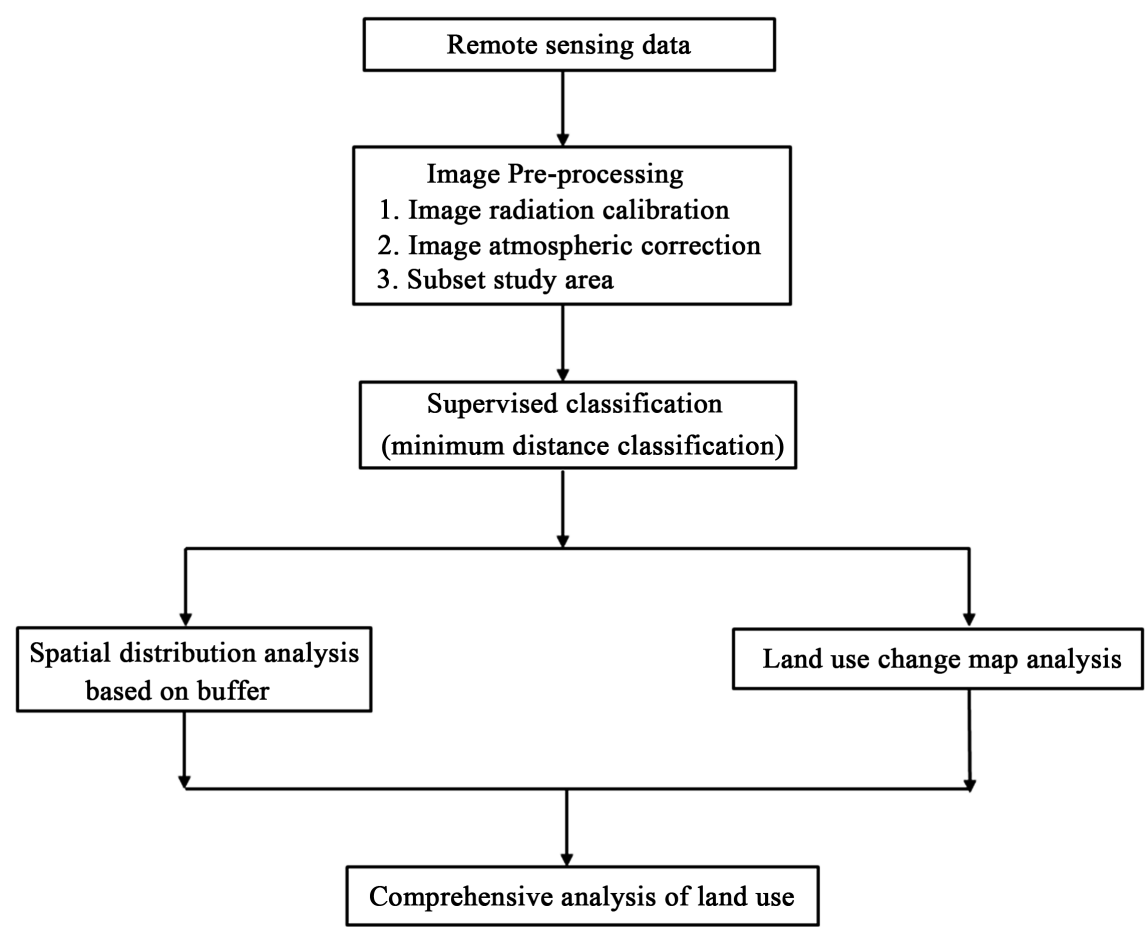

Figure 2. Flow chart of the classification procedure.

Table 2. Land use classification and assignment table.

\begin{tabular}{ccc}
\hline Classification of land use degree & Land use/cover types & Land use classification index \\
\hline Unused land grade & Unused land & 1 \\
Forest, grass and water level & Forest, water & 2 \\
Agricultural land grade & Cultivated land & 3 \\
Residential, industrial grade & Construction area & 4
\end{tabular}

value ranges from 100 - 400, the comprehensive index could directly reflect the degree of land use in a certain raster area. Based on that, the land use degree in any area can be obtained by calculating its comprehensive index.

\subsection{Map Information of Land Use Change}

Geo-information map which proposed by Chen and Yue [19] was a method using space-time integration map. It provides theoretical and method basis for investigating multi-dimension and multi-attribute features of geoscience research objects with temporal and spatial attributes. In this paper, we conduct map-algebraic fusion for two periods of land-use map units and complete the map fusion procedure. The fusion formula is:

$$
N=10 F+L
$$

In which, $N$ represents the raster map of the new map generated from land use change during the Characterization Study; $F$ represents the raster attributes of land use map units during the first period; $L$ represents the raster attributes of 
land use map units during the last period.

After obtaining the land use change map of the study area during these two periods, we calculated and recorded the attribute codes of each patch during the change procedure from first to last time period. Space-attribute-procedure integrated map units were synthesized.

The ratio of land use change represents the proportion of land use change types to all changes in the study area, which can further reflect characteristics of the quantitative change of land use change map units. The equation was as follows:

$$
P=\frac{S_{i j}}{\sum_{i=1}^{n} \sum_{j=1}^{n}(i+j)} \times 100 \%
$$

In which: $P$ is the change ratio; $S_{i j}$ is the area of map unit from the first type $i$ of land use during the first period to type $j$ of land use during the last period; $n$ is the number of land use types.

\section{Results and Discussion}

\subsection{Land Use Classification}

The information of land use change in the Yellow River Delta for many years revealed the impacts of human activities, climate change and soil conditions on land use of this area. The evolution pattern of landuse types is of great significance for ecological protection, species diversity maintain and reginal development direction.

The land use classification results of the study area from 2013 to 2017 were shown in Figure 3, and the variation of main land cover type was shown in Figure 4. Vegetation is the dominant land type in these years except for 2015 . Vegetation includes farmland, forest land and varieties of wetlands, which accounted for $32.79 \%$ in $2013,43.57 \%$ in $2014,41.84 \%$ in 2016 and $40.93 \%$ in 2017 of the total study area. The main reason of vegetation coverage decrease is the increase of bare land, while the crops were experienced first harvest in early June of 2015. The proportion of urban and rural residential area kept increasing year by year. The growth rate differed from $2.70 \%$ in 2013 to $4.12 \%$ in 2017 in the study area. With the rapid development of economy and the rapid growth of population, the demand for a large amount of construction area increased, and new factories, roads and residential areas have been built on cultivated area or unused land. According to the "High Efficiency Eco-economic Zone Development Planning of the Yellow River Delta" and the "Blue Economic Zone Development Planning of Shandong Peninsula" which officially approved by the State Council in 2009 and 2011, we could inferred that the urban expansion was closely related to the national strategy, and the two documents mentioned above would treat the Yellow River Delta region as an important component after 2009

[15]. As an important part of the national economic development strategy, the Yellow River Delta kept at a high economic development degree, the per capita 


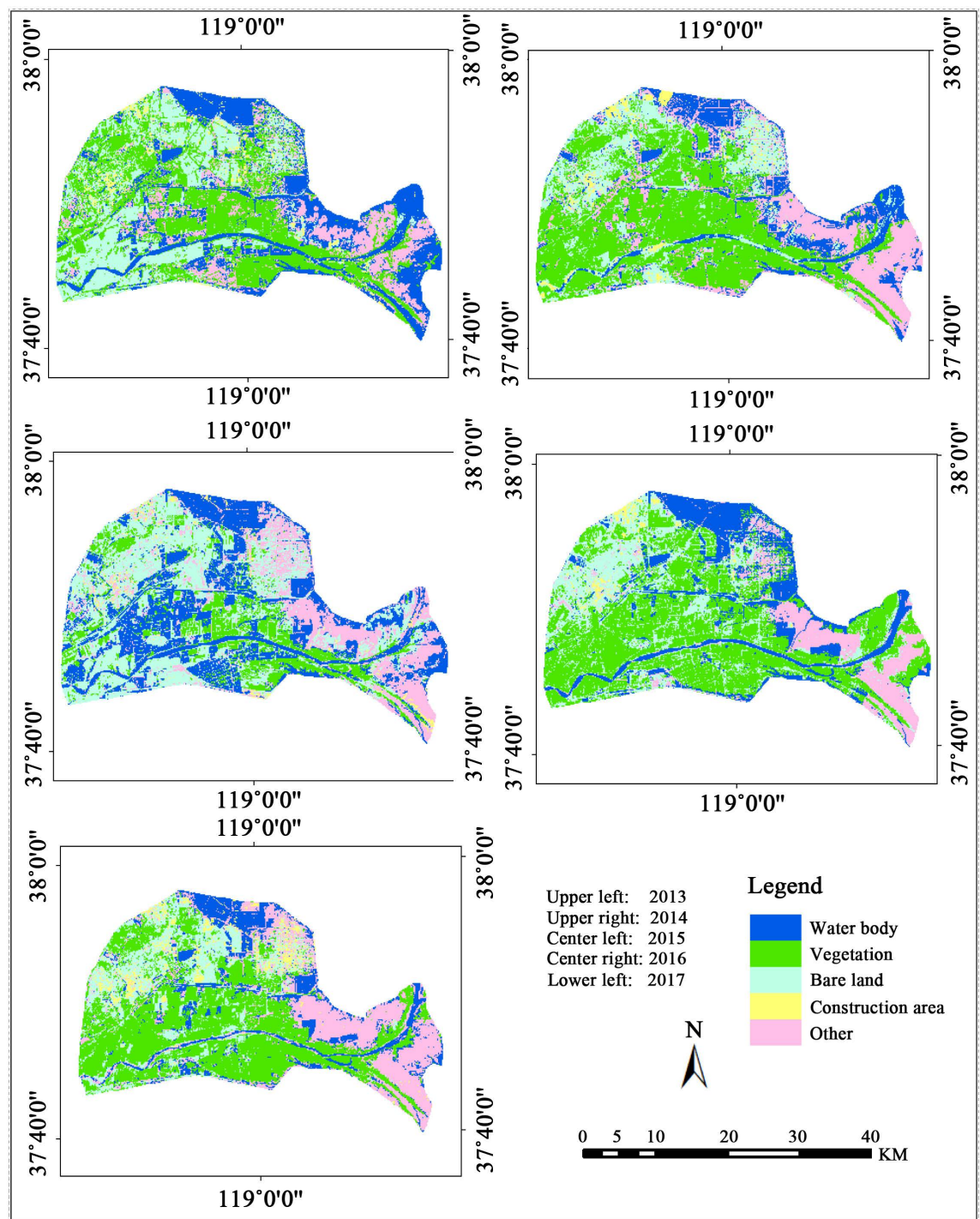

Figure 3. Maps of the land cover classification.

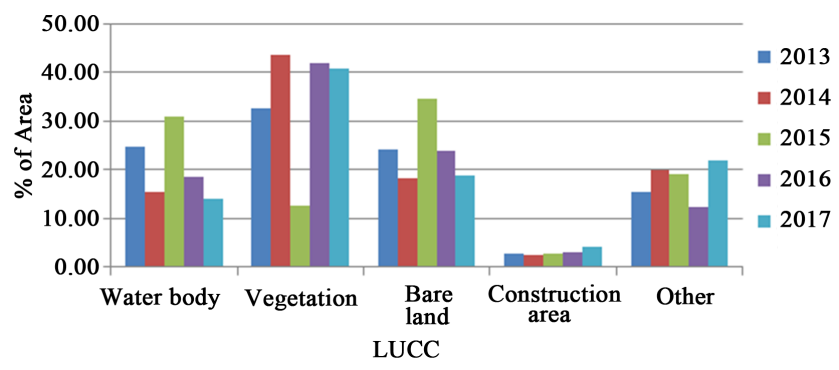

Figure 4. Changes in area of LULC featured classes during 2013-2017.

income has increased and urban area has expanded at a high speed, which has also led to the expansion of urban and rural settlements in the basin. Since most cities and towns were adjacent to rural settlements in the study area, rural settlements and towns have merged and expanded rapidly. Cities and towns have absorbed rural settlements in the process of expansion during the past five years. 
In general, the emergence of small patches and fragmentation of vegetation types gradually decreased, and farmland woodland, grassland and wetland began to take shape in 2016. The area of unused land, shallow sea water, forest land, grassland, inland water and coastal wetland decreased, while the area of cultivated land, constructed wetland and building increased on the whole. The comprehensive index of land use degree was $255.79,261.93,266.10$ and 268.82 in 2000, 2005, 2010 and 2015 respectively, showing a relatively significant increasing trend [20].

\subsection{Spatial Distribution Pattern of Land Use Degree Based on Buffer Zone}

The study of spatial distribution pattern involved multiple scales and objects. In this paper, regional statistics were introduced to analyze the change of land use degree in the buffer zones of different land use types including water body, vegetation, bare land, construction area and other land use types, from $20 \mathrm{~m}$ to 100 $\mathrm{m}$ [21]. The buffer zone of the construction area was set to $100 \mathrm{~m}$ and other land types of which was set to $20 \mathrm{~m}$ in this study. After that, further comprehensive discussion of the results was established, that can better explore the spatial distribution of land use degree in the study area.

1) The spatial distribution of land use degree which mainly composed of water body buffer zone. Several line charts were made as the results for the regional statistical analysis of water body, which have showed the spatial variation of the comprehensive index of land use degree. Figure 5 and Figure 6 have showed

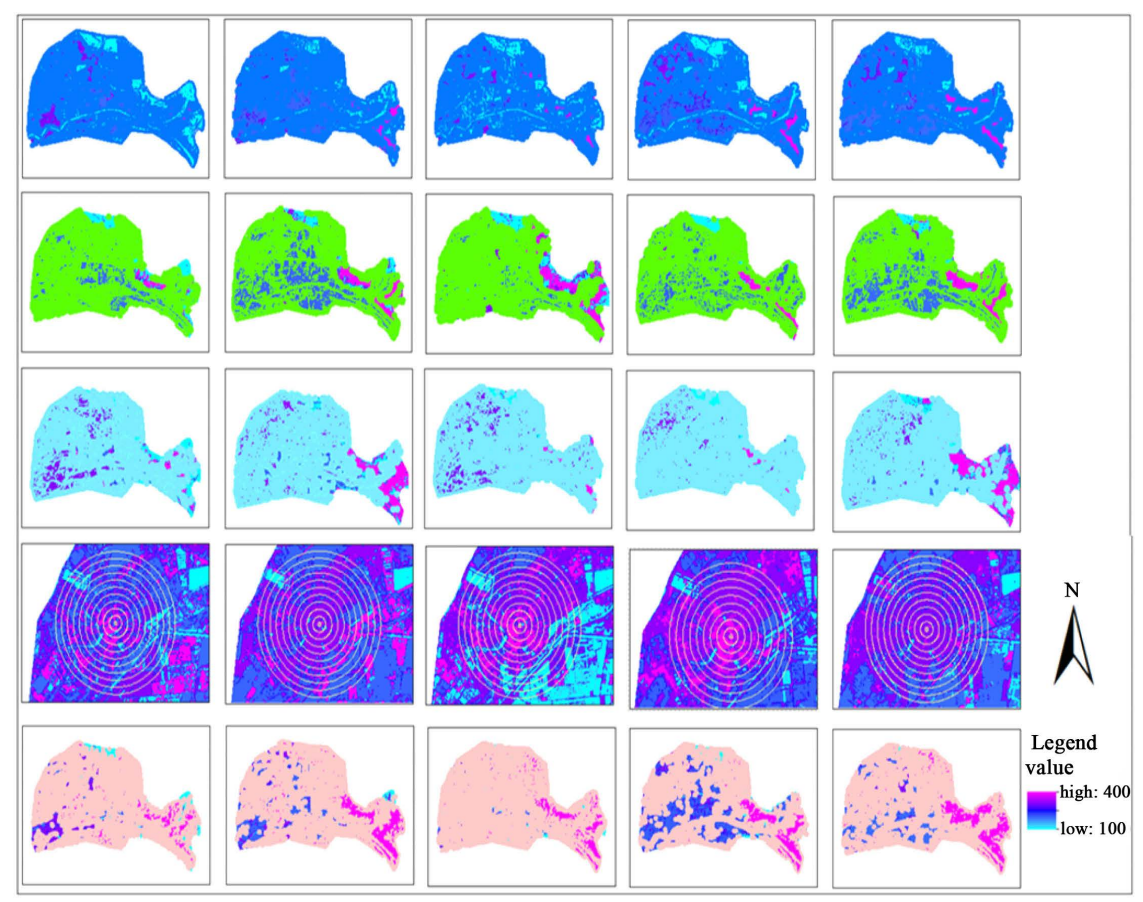

Figure 5. Map of comprehensive index of land use degree in buffer zones of different land use types. From top to bottom: water body, vegetation, bare land, construction area, other. 


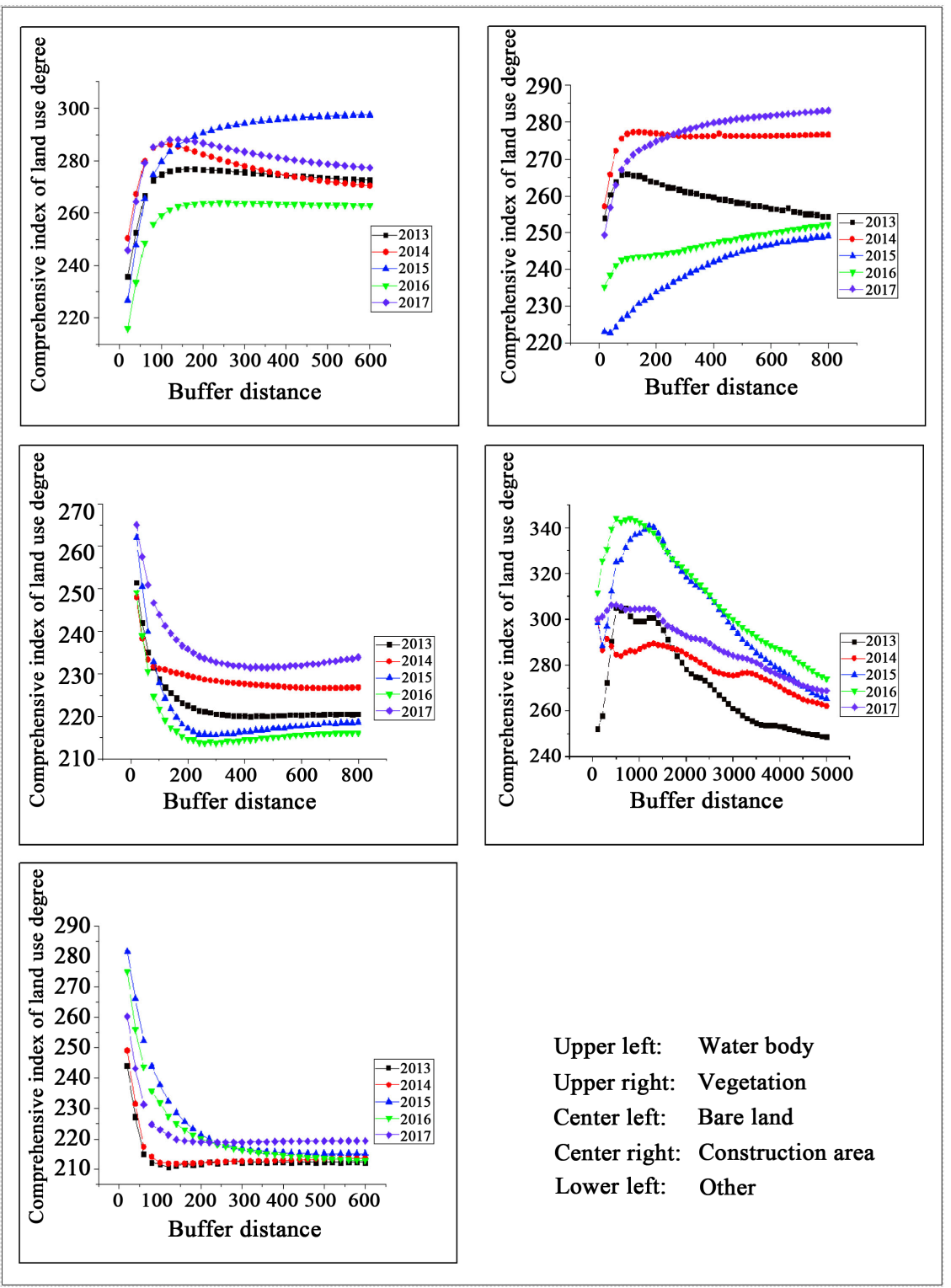

Figure 6. Buffer zone statistics of land use types.

that the index of land use degree around water body increased sharply at first and then tends to be flat during all the five time periods. In year 2013, 2014, 2016 and 2017, the index maximized at the buffer zone of $100 \mathrm{~m}$, which was 274.890 , $286.300,279.739,259.090$ and 286.383 respectively. In year 2015, the index first increased dramatically to 279.739 at $100 \mathrm{~m}$ buffer zone and then increased moderately to 296.000 at $400 \mathrm{~m}$ buffer zone. It was due to the $0-100 \mathrm{~m}$ area that close to the water body was the buffer zone between water body and construction area. In the $200-600 \mathrm{~m}$ area, since the increase of distance between rivers and water bodies and the impact of other topographic factors, the construction area gradually decreased while the area of farmland, cultivated land and various wetlands increased, and the comprehensive index tends to become moderate. The main land types of this area were farmland and wetland, and the intensity of 
human activities was low, and the land naturalization came to place. The 0 - 100 $\mathrm{m}$ buffer zone near the water area should be protected to prevent human activities from polluting the water body in the urban land use process.

2) The spatial distribution of land use degree which mainly composed of vegetation buffer zone. From the regional statistics of vegetation as shown in Figure 5 and Figure 6, we can distinguished that the trend of land use index varied with the change of distance between vegetation buffer zones in each year, which was mainly because the images for each year were of different time periods. Farmland and wetland types were greatly affected by seasonal variation, the index tend to increase in each year, except for 2013, the comprehensive index finally decreased and for 2014, the index variation eventually became moderate. The index increased briefly from 253.926, 257.091, 223.244, 235.235 and 249.344 to $265.908,276.821,227.652,242.964$ and 269.314 , respectively in the buffer zone of $0-100 \mathrm{~m}$ for each year. This was mainly due to the generally presence of a transition zone around $100 \mathrm{~m}$ distance from the forestland coupling with less human activity disturbance.

3) The spatial distribution of land use degree which mainly composed of bare land buffer zone. Figure 5 and Figure 6 showed that the tendency of the comprehensive index variation of land use degree around bare land was first sharply decline and then became moderate. At 0 - $200 \mathrm{~m}$ of bare land buffer zone, the comprehensive index of land use degree decreased from 251.501, 248.010, $262.021,249.136$ and 264.990 to $222.623,229.644,217.217,214.660$ and 235.791 respectively for five years in row. The average change rates were $16.043 \%$, $10.203 \%, 24.891 \%, 19.153 \%$ and $16.2217 \%$ respectively. The rapid decrease rate of the index is owing to the transition of land use types from bare land to farmland in this area. The index basically remained stable between $200 \mathrm{~m}$ and $800 \mathrm{~m}$ around bare land, since most land types in this area are farmland, forest and wetlands, the land use type remained unchanged, with barely development activities and the land was in the naturalization state. In land planning procedure, there should be a buffer zone reserved between bare land and other land types to prevent agricultural pollution from spreading to other types of land.

4) The spatial distribution of land use degree which was mainly composed of construction area buffer zone. From Figure 5 and Figure 6, it can be seen that the change of comprehensive index around construction area increased rapidly at first and then decreases rapidly, which maximized at about $1000 \mathrm{~m}$, with the maximum values being 299.366, 287.101, 337.479, 342.228 and 304.486, respectively. The intensity of land use within $1000 \mathrm{~m}$ of the construction area is high and the man-made disturbance ability was strong. The decline rate was $1.269 \%$, $0.621 \%, 1.800 \%, 1.704 \%$ and $0.890 \%$ respectively between $1000 \mathrm{~m}$ and $5000 \mathrm{~m}$. The land use types changed from construction area to farmland, wetlands, water body and other types of land. The intensity of land development decreased rapidly. Since this area is adjacent to the border of the study area, and there were many breeding base and wetland distributed along the border. The degree of land naturalization was high. The key point in urban planning and land man- 
agement was to control the disorderly expansion of construction area.

5) The spatial distribution of land use degree which was mainly composed of other lands buffer zone. The index around other land declined sharply at 0 - 140 $\mathrm{m}$ first and then tended to be flat. The comprehensive index decreased sharply from 243.956, 249.028, 281.575, 275.133 and 260.283 to 211.281, 211.914, $228.613,225.063$ and 219.831 respectively and the difference values were 32.675 , $37.114,52.962,50.070$ and 40.452. Unused land was replaced by other types of land, which leading to the increase of land use intensity. The land type gradually transferred to wetlands and farmland, and the index variation tended to be flat between $140 \mathrm{~m}$ and $600 \mathrm{~m}$. The proportion of other land types among all the land use types in the study area was small and fragmented, so the unused land could be protected in the planning program.

\subsection{Analysis of Land Use Transfer Map}

Land use transfer map of the Yellow River Delta from 2013 to 2017 generated 25 types of map units, of which 20 types have showed transformation in land types [22] [23]. The significant regional differences in spatial distribution were shown in Figure 7. The sequence of map units according to area size was shown in Table 3. The change rate was also calculated among which the highest one was $20.21 \%$ accounting for map unit of bare land to vegetation (code 32). Chinese government has issued the Land Management Law in order to strengthen the protection of cultivated land, which clearly specified the rules of compensation for cultivated land occupation, also the protection measures of balance between occupation and compensation of non-cultivated land were implemented. Therefore, the exploit of bare land has been strengthened, which resulting in a

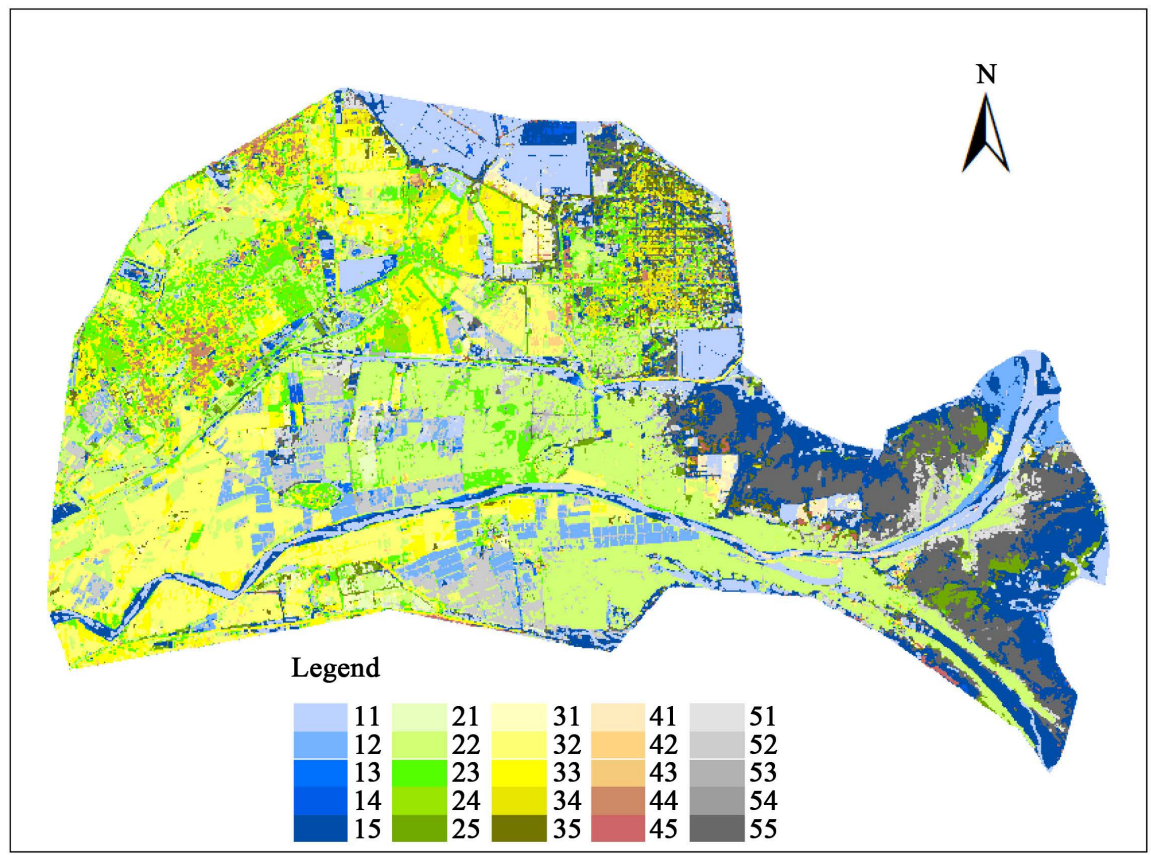

Figure 7. Map of land use transfer in time sequence units. 
Table 3. Sequence table of map units of land use change types from 2013 to 2017.

\begin{tabular}{|c|c|c|c|c|}
\hline Code & Land use transfer map unit & $\begin{array}{c}\text { Number of map } \\
\text { units/numbers }\end{array}$ & $\begin{array}{c}\text { Transfer } \\
\text { area } / \mathrm{km}^{2}\end{array}$ & $\begin{array}{l}\text { Change } \\
\text { ratio/\% }\end{array}$ \\
\hline 32 & Bare land $\rightarrow$ Vegetation & 111,309 & 100.178 & 20.21 \\
\hline 15 & Water body $\rightarrow$ Other & 105,908 & 95.317 & 19.23 \\
\hline 23 & Vegetation $\rightarrow$ Bare land & 77,910 & 70.120 & 14.15 \\
\hline 52 & Other $\rightarrow$ Vegetation & 53,180 & 47.862 & 9.66 \\
\hline 12 & Water body $\rightarrow$ Vegetation & 42,838 & 38.554 & 7.78 \\
\hline 25 & Vegetation $\rightarrow$ Other & 27,089 & 24.380 & 4.92 \\
\hline 34 & Bare land $\rightarrow$ Construction land & 19,339 & 17.405 & 3.51 \\
\hline 51 & Other $\rightarrow$ Water body & 18,180 & 16.362 & 3.30 \\
\hline 35 & Bare land $\rightarrow$ Other & 17,459 & 15.713 & 3.17 \\
\hline 21 & Vegetation $\rightarrow$ Water body & 15,527 & 13.974 & 2.82 \\
\hline 53 & Other $\rightarrow$ Bare land & 12,693 & 11.424 & 2.30 \\
\hline 31 & Bare land $\rightarrow$ Water body & 11,503 & 10.353 & 2.09 \\
\hline 13 & Water body $\rightarrow$ Bare land & 9318 & 8.386 & 1.69 \\
\hline 24 & Vegetation $\rightarrow$ Construction land & 5599 & 5.039 & 1.02 \\
\hline 14 & Water body $\rightarrow$ Construction land & 4850 & 4.365 & 0.88 \\
\hline 45 & Construction land $\rightarrow$ Other & 4462 & 4.016 & 0.81 \\
\hline 41 & Construction land $\rightarrow$ Water body & 4370 & 3.933 & 0.79 \\
\hline 43 & Construction land $\rightarrow$ Bare land & 4289 & 3.860 & 0.78 \\
\hline 42 & Construction land $\rightarrow$ Vegetation & 3425 & 3.083 & 0.62 \\
\hline \multirow[t]{2}{*}{54} & Other $\rightarrow$ Construction land & 1472 & 1.325 & 0.27 \\
\hline & Total & 550,720 & 495.648 & 100.00 \\
\hline
\end{tabular}

large number of bare lands transformed into cultivated land. The second highest rate belongs to "the water body into other land" (code 15). The area of the transfer patches which mainly distributed in the coastal area of the Yellow River Delta was $95.317 \mathrm{~km}^{2}$. In this area, due to the movement of coastline to the east, the offshore area turned into beach. Many small ponds disappeared and transferred to other land types referring to remote sensing images. The third highest rate is vegetation to bare land (code 23), which accounted for $14.15 \%$ of the total rate. This unit mainly distributed around urban construction area. Due to the rapid development of economy, the sharp expansion of construction area for transportation and residence, coupled with relatively flat terrain, a large number of bare land and cultivated land have transformed into construction area of which the area was $17.405 \mathrm{~km}^{2}$ and $5.039 \mathrm{~km}^{2}$ respectively. However, the percentage of construction area transformation was relatively small, only 14.891 $\mathrm{km}^{2}$. Compared with other time periods, the change trend was more obvious, water bodies and salt fields increased greatly, the tidal flats decreased significantly, the tendency of land use type conversion became more and more obvious, and the conversion rate gradually stabilized from 2010 to 2014 [24]. 


\section{Conclusions}

This research employed the spatial distribution pattern of land use degree which is based on regional statistical data in the buffer zone to analyze the spatial and temporal characteristics of land use/cover in the past five years, which was on the basis of the processed multi-temporal remote sensing images of the Yellow River Delta. Here came the results:

The comprehensive index of land use degree in the study area was between 0 and 400. The land use degree in most of the study area was at medium level, and the area which belongs to relatively high land use degree was centralized around the water body and vegetation covered area. It is necessary for planning department to protect and exploit the area with high land use degree in a reasonable way. The setting of buffer zone also needed to be paid close attention to. The key emphasis is on monitoring the $100 \mathrm{~m}$ area around the water body, $100 \mathrm{~m}$ around the vegetation, $200 \mathrm{~m}$ around the bare land, $1000 \mathrm{~m}$ around the construction area and $140 \mathrm{~m}$ around other land. Attention should be paid to the continuity of land planning to prevent over occupation of cultivated land and maintain land security.

The bare land area decreased $49.86 \mathrm{~km}^{2}$ and the salt wasteland was transformed into forest, grassland and farmland, while the vegetation area increased $76.17 \mathrm{~km}^{2}$ in five years. The construction area in the Yellow River Delta region has shown a rapid expansion trend and a high land use degree, which reflected the tendency of rapid urbanization in the study area. The main difficulties of wetland protection at present are the continuity demand of land for urban expansion and extensive land management. In future land use planning and land resource allocation process, we should reasonably plan and design the scale of urban construction, coordinate the relationship between urbanization, economic development and cultivated land protection, adhere to the arable land minimum, follow the spatial distribution pattern of land use transformation, and adjust the land use pattern and structure according to local conditions for giving full play to the advantages of regional resources edowments.

The natural driving forces of land use/cover change were sediment deposition along the Yellow River and sea erosion. The main social economical driving forces were the impacts of rapid population growth, economic development and the land use policy regulation.

\section{Acknowledgements}

The authors would like to thank the Resource and Environmental Science Data Center of the Chinese Academy of Sciences for providing free Lands at 8 OLI data, Point of Interest (POI) data and $1 \mathrm{~km}$ raster data.

\section{Conflicts of Interest}

The authors declare no conflicts of interest regarding the publication of this paper. 


\section{References}

[1] Li, H., Wang, Y.P., Li, Y., Wang, X.F. and Tao, L. (2011) Spatial Autocorrelation Analysis on Land Use Change in the Pearl River Delta. Ecology and Environmental Sciences, 20, 1879-1885.

[2] Ottinger, M., Kuenzer, C., Liu, G., Wang, S. and Dech, S. (2013) Monitoring Land Cover Dynamics in the Yellow River Delta from 1995 to 2010 Based on Landsat 5 TM. Applied Geography, 44, 53-68. https://doi.org/10.1016/j.apgeog.2013.07.003

[3] Butt, A., Shabbir, R., Ahmad, S.S., Aziz, N., Nawaz, M. and Shah, M.T.A. (2015) Land Cover Classification and Change Detection Analysis of Rawal Watershed Using Remote Sensing Data. Journal of Biodiversity and Environmental Sciences, 6, 236-248.

[4] Ganguly, K., Kumar, R., Mruthyunjaya Reddy, K., Jagadeeswara Rao, P., Raj Saxena, M. and Ravi Shankar, G. (2017) Optimization of Spatial Statistical Approaches to Identify Land Use/Land Cover Change Hot Spots of Pune Region of Maharashtra Using Remote Sensing and GIS Techniques. Geocarto International, 32, 777-796. https://doi.org/10.1080/10106049.2016.1178813

[5] Tran, D.X., Pla, F., Latorre-Carmona, P., Myint, S.W., Caetano, M. and Kieu, H.V. (2017) Characterizing the Relationship between Land Use Land Cover Change and Land Surface Temperature. ISPRS Journal of Photogrammetry and Remote Sensing, 124, 119-132. https://doi.org/10.1016/j.isprsjprs.2017.01.001

[6] Samie, A., Deng, X., Jia, S. and Chen, D. (2017) Scenario-Based Simulation on Dynamics of Land-Use-Land-Cover Change in Punjab Province, Pakistan. Sustainability, 9, 1285. https://doi.org/10.3390/su9081285

[7] Gounaridis, D., Symeonakis, E., Chorianopoulos, I. and Koukoulas, S. (2018) Incorporating Density in Spatiotemporal Land Use/Cover Change Patterns: The Case of Attica, Greece. Remote Sensing, 10, 1034. https://doi.org/10.3390/rs10071034

[8] Liu, H.H., Liu, Y.X., Zhang, C.H., Yang, X.M., Hu, J. and Li, J. (2018) Study on Monitoring Wetland Change by Remote Sensing in the Yellow River Delta from 1991 to 2016. Earth and Environment, 46, 590-598.

[9] Ansari, A. and Golabi, M.H. (2019) Prediction of Spatial Land Use Changes Based on LCM in a GIS Environment for Desert Wetlands-A Case Study: Meighan Wetland, Iran. International Soil and Water Conservation Research, 7, 64-70. https://doi.org/10.1016/j.iswcr.2018.10.001

[10] Barakat, A., Ouargaf, Z., Khellouk, R., El Jazouli, A. and Touhami, F. (2019) Land Use/Land Cover Change and Environmental Impact Assessment in béni-mellal District (Morocco) Using Remote Sensing and GIS. Earth Systems and Environment, 3, 113-125. https://doi.org/10.1007/s41748-019-00088-y

[11] Guo, C.Y., Gao, S., Zhou, B.Y. and Gao, J.H. (2019) Study on the Impact of Land Use Change on Eco-Service Value Based on Grid in Funiu Mountain Area. Acta Ecologica Sinica, 39, 3482-3493.

[12] Li, X.Y. and Kuang, W.H. (2019) Spatial-Temporal Trajectory and Future Scenario Simulation of Urban Land Use Change in Beijing, Tianjin and Hebei from 1980 to 2015. Economic Geography, 39, 187-194+200.

[13] Hasmadi, M., Pakhriazad, H.Z. and Shahrin, M.F. (2017) Evaluating Supervised and Unsupervised Techniques for Land Cover Mapping Using Remote Sensing Data. Malaysian Journal of Society and Space, 5, 1-10.

[14] Chen, L. and Ren, C.Y. (2017) Interpretation Symbol of the Coastal Wetlands in the Yellow River Delta. Wetland Science, 15, 179-186. 
[15] Lang, K., Zhao, G.X., Wang, W.Q., Zhang, S.M. and Xiao, Y. (2019) Analysis of Land Use Dynamic Characteristics in Typical Areas of the Yellow River Delta in Recent 10 Years. Geospatial Information, 17, 75-80+5.

[16] Zubaida, M., Xia, J.X., Polat, M. and Zhang, R. (2019) Study on Land Use/Cover and Landscape Pattern Change in the Middle Reaches of the Creya River. Acta Ecologica Sinica, 39, 2322-2330. https://doi.org/10.5846/stxb201804270954

[17] Liu, G., Zhang, Q., Li, G. and Doronzo, D.M. (2016) Response of Land Cover Types to Land Surface Temperature Derived from Landsat5 TM in Nanjing Metropolitan Region, China. Environmental Earth Sciences, 75, 1386. https://doi.org/10.1007/s12665-016-6202-4

[18] Liu, J.Y. (1996) Macroscopic Investigation and Dynamic Research of Resources and Environment Remote Sensing in China. Press of University of Science and Technology of China, 86-186.

[19] Chen, S.P. and Yue, T.X. (2000) Studies on Geo-Informatic Tupu and Its Application. Geographical Research, 19, 337-343.

[20] Song, B.Y. and Hou, X.Y. (2019) Landuse Change Characteristics and Scenario Analysis in the Yellow River Delta and Laizhou Bay Coastal Zone. Marine Science, 43, 24-34.

[21] Lin, L., Xu, Z.H., Huang, X.Y. and Shi, T.T. (2019) Spatial Distribution of Land Use Degree Based on Buffer Zone Analysis: A Case Study of Mawei District, Fuzhou City. Remote Sensing Information, 34, 135-143.

[22] Ye, Q.H., Liu, G.H., Tian, G.L., Ye, J.M., Chen, S.L., Huang, C., Liu, Q.S., Chang, J., Shi, Y.N. and Lou, W.G. (2004) Analysis of Spatial-Temporal Compound Change Atlas of Land Use in the Yellow River Delta. Science in China, Ser. D, No. 5, 461-474.

[23] Yu, Y.H., Li, Z.J., Lin, J.K., Liu, J.Y. and Wang, S. (2019) Characteristic Analysis of Spatial and Temporal Change Map of Land Use in Yihe River Basin. Journal of Natural Resources, 34, 975-988.

[24] Li, C., Li, G.E. and Xie, Z.W. (2015) Analysis of the Land Use History and the Causes in Yellow River Delta during the Last 15 Years. Science \& Technology Review, 33, 37-44. 